\title{
Correspondence
}

\section{Microscopic findings in a neurogenic bladder caused by myelomeningocele}

Spinal Cord (2005) 43, 65-66. doi:10.1038/sj.sc.3101654; Published online 10 August 2004

It is well known that urinary incontinence, retention and urinary tract infections are common complications in patients with neurogenic bladder dysfunction. ${ }^{1}$ In the following, we would like to share our experience with a young female patient suffering from congenital myelomeningocele and internal hydrocephalus. At the age of 1 year, the left kidney had to be removed because of hydronephrosis. Subsequently, there have been repeated bouts of cystitis and the patient has remained dependent on catheterisation (5 times a day). Bladder capacity decreased to $30 \mathrm{ml}$ before the second operation at the age of 13 years. Cystectomy and an intestinal ureterostomy were performed. This operative procedure, first described by Zaayer in 1911, was established as a standard urological technique by Bricker in $1950 .^{2}$

Macroscopical examination showed the urinary bladder to be of subnormal size, measuring $4 \times 4 \times 4 \mathrm{~cm}$. The thick bladder wall was nonelastic and fibrotic. On the internal surface, the mucosa was irregularly greyishwhite.

On microscopical examination, the cystectomy specimen presented severe fibrosis in the lamina propria and muscularis. Some of the affected areas were rich in collagen fibres, as visualised by the Masson-Trichrome stain. Other regions of the bladder wall showed paucicellular hyalinisation. There was disarray of smooth muscle cells on a background of fibrosis as well as leiomyomatous-like hyperplasia (Figure 1). Rare lymphoplasmacellular inflammatory infiltrates were found in the lamina propria. Most parts of the mucosa were covered with typical umbrella cells. Small regions presented squamous metaplasia. On immunohistochemistry, the umbrella cells showed no cytoplasmic expression of cytokeratin 20. Staining for S-100 protein, an antigen expressed by Schwann cells of peripheral nerves revealed marked hypertrophy and hyperplasia of the nerve fibres in the lamina propria and the muscularis. These findings could be interpreted as a reaction to persistent mechanical strain on the bladder wall. This case illustrates severe morphological changes of the urinary bladder induced primarily by neurogenic deficiency and complicated by superimposed chronic inflammation.

Literature data regarding microscopic findings in the urinary bladder of patients with a myelomeningocele are scarce. The patient described herein showed no

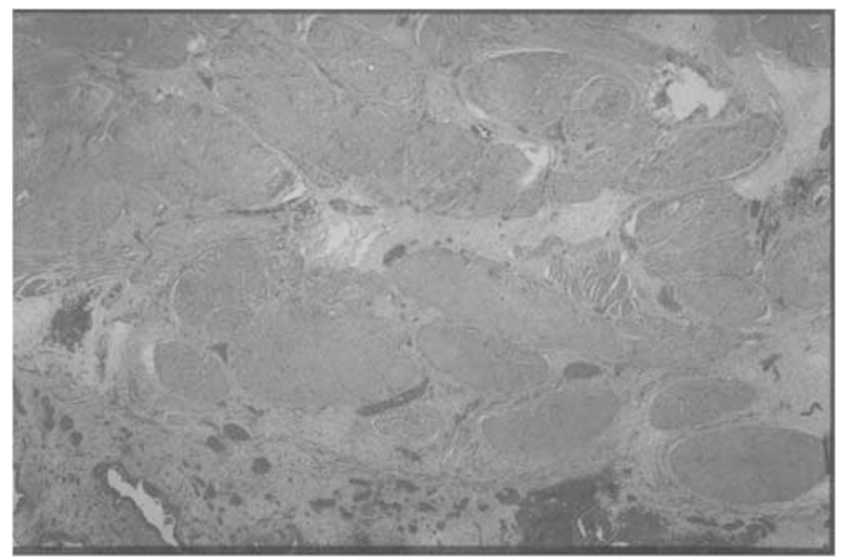

Figure 1 Microscopic aspect of a neurogenic urinary bladder caused by myelomeningocele-presenting leiomyomatous-like hyperplasia of the muscularis, increased fibrosis and chronic inflammatory infiltrates in the lamina propria (haematoxylineosin stain, original magnification $\times 60$ )

signs of dysplastic or malignant change of the urothelium. Recently, a clinicopathological study focusing on urothelial differentiation in patients with spinal cord injury was published. ${ }^{3}$ In approximately $80 \%$ of those cases, an absence of immunostaining for cytokeratin 20 was found, which corresponds to the so-called 'incomplete' urothelial differentiation leading to a greater risk of developing inflammation and dysplasia.

Until now, the mechanism predisposing to urothelial dysplasia and transitional cell carcinoma in the neuropathic bladder remains unclear. Nevertheless, patients with neurogenic bladder dysfunction are at increased risk of developing some form of urothelial malignancy and should, therefore, be followed carefully. ${ }^{4}$ Consensus regarding the modalities of screening including regularly bioptical controls has not been formed yet. ${ }^{5}$

J Janzen $^{1}$ and BM Soni ${ }^{2}$

${ }^{1}$ Arzt für Pathologie, Institut für Pathologie, Universität Tübingen, Liebermeisterstrasse 8, D-72076 Tübingen, Germany; ${ }^{2}$ Consultant in Spinal Injuries, Regional Spinal injuries centre, Southpork \& Ormskirk Hospital, Merseyside, $U K$ 


\section{Acknowledgements}

We thank Dr Istvan Vajtai, Brunnhof AG, Bern, Switzerland for his critical comments and Andreas Maurus.

\section{References}

1 Matsumoto $\mathrm{T}$, Takahashi $\mathrm{K}$, Manabe $\mathrm{N}$, Iwatsubo $\mathrm{E}$, Kawakami Y. Urinary tract infection in neurogenic bladder. Int J Antimicrob Agents 2001; 17: 293-297.

2 Pannek J, Senge T. History of urinary diversion. Urol Int 1998; 60: $1-10$.
3 Vaidyanathan $\mathrm{S}$ et al. A study of cytokeratin 20 immunostaining in the urothelium of neuropathic bladder of patients with spinal cord injury. BMC Urol 2002; 2: $7-15$.

4 Janzen J, Bersch U, Pietsch-Breitfeld B, Pressler H, Michel D, Bültmann B. Urinary bladder biopsies in spinal cord injured patients. Spinal Cord 2001; 39: $568-570$.

5 Hamid R, Bycroft J, Arya M, Shah PJR. Screening cystoscopy and biopsy in patients with neuropathic bladder and chronic suprapubic indwelling catheters: is it valid? J Urol 2003; 170: 425-427. 